OPEN ACCESS

Edited by:

Xu Wang,

Harvard Medical School,

United States

Reviewed by:

Ajay Singh Karakoti,

The University of Newcastle, Australia

Tawfik A. Saleh,

King Fahd University of Petroleum and

Minerals, Saudi Arabia

${ }^{*}$ Correspondence:

Xin Du

xdu@sdnu.edu.cn

Specialty section:

This article was submitted to

Nanoscience,

a section of the journal

Frontiers in Chemistry

Received: 01 April 2020

Accepted: 22 June 2020

Published: 11 August 2020

Citation:

Zhang C and Du X (2020)

Electrochemical Sensors Based on

Carbon Nanomaterial Used in

Diagnosing Metabolic Disease.

Front. Chem. 8:651.

doi: 10.3389/fchem.2020.00651

\section{Electrochemical Sensors Based on Carbon Nanomaterial Used in Diagnosing Metabolic Disease}

\author{
Congcong Zhang and Xin Du* \\ Shandong Provincial Key Laboratory of Animal Resistance Biology, Key Laboratory of Food Nutrition and Safety, College of \\ Life Sciences, Shandong Normal University, Jinan, China
}

Metabolic diseases have become common diseases with the improvement of living standards because of changed dietary habits and living habits, which seriously affect health. Currently, related biomarkers have been widely used as important indicators for clinical diagnosis, treatment, and prognosis of metabolic diseases. Among all detection methods for biomarkers of metabolic diseases, electrochemical sensor technology has the advantages of simplicity, real-time analysis, and low cost. Carbon nanomaterials were preeminent materials for fabricating electrochemical sensors in order to enhance the performance. In this paper, we summarize the research progress in the past 3 years of electrochemical sensors based on carbon nanomaterials in detecting markers of metabolic diseases, which include carbon nanotubes, graphene, carbon quantum dots, fullerene, and carbon nitride. Additionally, we discuss the future prospects for this field.

Keywords: metabolic disease, biomarkers, electrochemical sensors, carbon nanomaterials, detection

\section{INTRODUCTION}

Human life activities are inseparable from metabolism, and the stability of metabolic activity plays a very important role in maintaining human health. Once metabolic dysfunction occurs, it can lead to the occurrence of a variety of diseases. Metabolic diseases are usually caused by metabolic problems, including metabolic disorders and metabolic exuberance (Cani, 2019; Sanna et al., 2019). Metabolic diseases mainly include diabetes mellitus (DM) (Maiese, 2020), non-alcoholic fatty liver disease (NAFLD) (Colca, 2020), gout (Oh et al., 2019), vitamin deficiency (Kim et al., 2015), diabetic ketoacidosis (Musso et al., 2019), and other diseases which can also lead to a variety of complications. The metabolic disease will further cause atherosclerosis and other cardiovascular diseases if the patient is not treated in time. These diseases not only affect normal diet and activities but also pose a threat to health and normal life (Clemmensen et al., 2019).

Taking DM as an example, DM is a group of metabolic diseases characterized by hyperglycemia (Rosik et al., 2020). The traditional diagnostic methods for detecting infectious diseases include routine blood test, biochemical test, routine urine test, and glucose tolerance tests that are often expensive, time-consuming, and labor-intensive (Sahin et al., 2018; Salek-Maghsoudi et al., 2018). Compared with traditional detection methods, electrochemical biosensor technology has been increasingly applied due to its unique advantages ( Du and Zhou, 2018; Maduraiveeran et al., 2018). Nanostructured carbon-based materials, such as carbon nanotubes (Chen et al., 2016a,b), graphene (Janegitz et al., 2017; Abellan-Llobregat et al., 2018; Taniselass et al., 2019), carbon quantum dots (Ren, 2015; Ding et al., 2020), fullerenes (C60) (Kawase et al., 2003), and 
carbon nitride (Zhang P. et al., 2019) have gained enormous attention in preparing electrochemical biosensors for their high durability, excellent electrical conductivity, and excellent biocompatibility. According to the research progress, biosensors can match or even surpass traditional methods due to the excellent performance of electrochemical sensors (Rombout et al., 2014; Du et al., 2020). The development of nanomaterials and electronic technology has accelerated the development of electrochemical biosensing technique which provides a new method for rapid detecting in biomarkers of metabolic diseases.

Metabolic disease biomarkers, as important indicators for clinical diagnosis, treatment reference, and prognosis judgment, have been widely used (Liang et al., 2010; Liu M. et al., 2018; Wang et al., 2018). For example, ascorbic acid (AA) (Hsine et al., 2020), uric acid (UA) (Iranmanesh et al., 2020), leptin (Guo et al., 2015), 3-hydroxybutyrate (3-HB), and glucose are important biological molecules indispensable to the human body. For instance, the main cause of scurvy is lack of AA. Vitamin D can regulate calcium and phosphorus homeostasis and control bone metabolism, whose deficiency is associated with rickets in children and osteomalacia in adults (Pittas et al., 2019). The deficiency of vitamin D has also been linked to DM (Sassi et al., 2018; Bouillon et al., 2019). Methylglyoxal (MG) can be treated as an emerging biomarker for DM diagnosis; meanwhile, it also plays a crucial role in biological processes in hypertension and nephropathy (Maessen et al., 2015). The concentration of $3-\mathrm{HB}$ is related to diabetic ketoacidosis (Liu et al., 2015; Rodriguez-Gallego et al., 2015). High levels of UA in the blood is the cause of gout (Cui et al., 2011; Ding et al., 2018). Leptin and acetaminophen metabolism can be used as biomarkers for the diagnose of NAFLD (A-Kader et al., 2010; Perez-Perez et al., 2017). Therefore, the rapid and accurate determination of the concentrations of these biomarkers in the human body is of great significance for the study of human physiological functions and the diagnosis and prevention of diseases.

\section{PRINCIPLE OF ELECTROCHEMICAL SENSOR}

Electrochemical detection method means that the electrochemical biosensor is constructed to realize rapid detection, which is mainly used in biocomponents such as antibodies and enzymes to modify electrodes (Tilmaciu and Morris, 2015). When the original biocomponents react with the specific target analyte, the reaction can be confirmed and measured; meanwhile, electrical signals are generated which are processed by the electronic system and then become the information that we can observe directively. Common detection methods of electrochemical sensor mainly contain linear sweep voltammetry (LSV), cyclic voltammetry (CV), and differential pulse voltammetry (DPV). The principle of electrochemical sensors based on carbon nanomaterials in detecting metabolic disease biomarkers is shown in Figure 1.

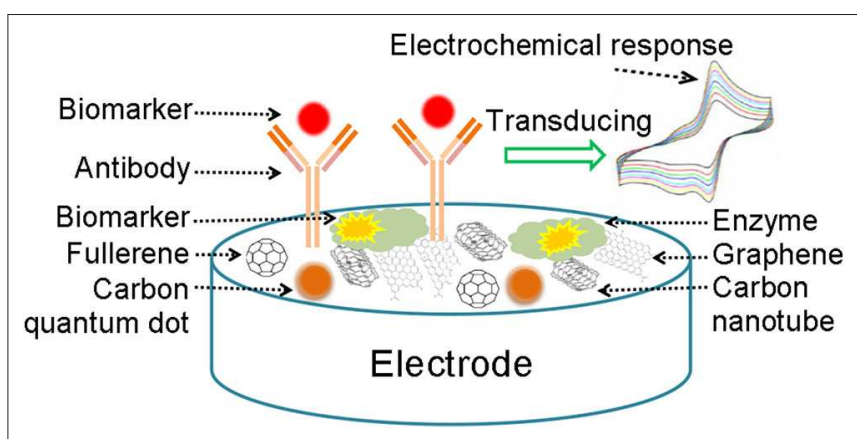

FIGURE 1 | A schematic representation of electrochemical biosensor.

\section{APPLICATION OF CARBON NANOMATERIALS IN METABOLIC DISEASE DETECTION}

In recent years, increasing attention has been paid to the detection of metabolic disease biomarkers by electrochemical biosensors. Therefore, this paper reviews the latest research progress of several different carbon nanomaterials in electrochemical biosensor detection of common markers of metabolic diseases. The performance of the sensors introduced in this review was summarized as shown in Table $\mathbf{1}$.

\section{Carbon Nanotubes}

Carbon nanotubes (CNTs) are one of the most thoroughly studied materials with $\mathrm{sp}^{2}$ hybridized carbon bonds (Yang et al., 2019), which usually include multi-walled carbon nanotubes (MWCNTs), and single-walled carbon nanotube (SWCNT) (Quintero-Jaime et al., 2019). Their fascinating structures have attracted attention of numerous researchers. CNTs are seamless nanoscale tubes made of a single or multilayer graphite coiled at a certain helical angle around a central axis (De Volder et al., 2013; Noyce et al., 2019). Because of its wide range of thermal, structural, and electronic properties, they have been applied to catalyst and capacitor material support (Gong et al., 2013; Yang et al., 2017). And owing to the unique stability of the side wall and tubular structure of carbon nanotubes, they also could be used as an ideal template or carrier for other nano materials, especially nanowires (El-Nashar et al., 2012).

In 2017, Rajabi and Noroozifar (2017) used a new synthesis method to synthesize the peg-methoxyaniline nanostructure, and then successfully constructed a MWCNT of the star. The electrochemical biosensor constructed by this method had the advantages of sensitivity, simplicity, and low cost, which can simultaneously detect UA and folic acid in the real samples. In 2018, Abellan-Llobregat et al. (2018) developed a novel portable electrochemical sensor to detect AA and UA simultaneously. The sensitivity and reproducibility were tested and the results were favorable. This method had been triumphantly applied to the real samples. In the next year, Lv et al. (2019) used an electrochemical sensor constructed by porous $g-\mathrm{C}_{3} \mathrm{~N}_{4}$ (PCN) 
TABLE 1 | Comparison of electrochemical sensors based on carbon nanomaterials for detecting biomarkers of metabolic diseases.

\begin{tabular}{|c|c|c|c|c|c|c|}
\hline $\begin{array}{l}\text { Carbon } \\
\text { nanomaterial }\end{array}$ & $\begin{array}{l}\text { Disease } \\
\text { biomarker }\end{array}$ & $\begin{array}{c}\text { Linear } \\
\text { range }(\mu \mathrm{M})\end{array}$ & $\begin{array}{l}\text { Detection } \\
\text { limit }(\mu M)\end{array}$ & Reproducibility & Stability & References \\
\hline CNT & UA & $0.6-52$ & 0.157 & - & - & Rajabi and Noroozifar, 2017 \\
\hline CNT & $\mathrm{AA}, \mathrm{UA}$ & - & 0.65 & $7 \%$ & - & Abellan-Llobregat et al., 2018 \\
\hline CNT & UA & $0.2-4,4-20$ & 0.139 & $2.20 \%$ & $95 \%$ (2 weeks) & Lv et al., 2019 \\
\hline CNT & $\mathrm{AA}, \cup \mathrm{A}$ & $200-400,2-16$ & $40.0,0.73$ & $\begin{array}{l}0.77 \% \\
2.87 \%\end{array}$ & $\geq 92.5 \%$ (15 days) & Zhang S. et al., 2019 \\
\hline CNT & UA & $20-2700$ & 2.8 & $1.30 \%$ & $90 \%(24 \mathrm{~h})$ & Fukuda et al., 2020 \\
\hline CNT & UA & $7-20$ & 2.4 & $4.71 \%$ & 95\% (20 days) & Manjunatha et al., 2018 \\
\hline Graphene & UA & $0.5-100$ & 0.053 & - & $91.6 \%$ (2 weeks) & Pang et al., 2020 \\
\hline Graphene & UA & $0.02-783.6$ & $1.2 \times 10^{-4}$ & $3.28 \%$ & $96.42 \%$ (30 days) & Sriram et al., 2019 \\
\hline Graphene & UA & $50-800$ & $7.32 \pm 0.21$ & $4.60 \%$ & $90.0 \%$ (6 months) & Verma et al., 2019 \\
\hline Graphene & $\mathrm{AA}, \mathrm{UA}$ & $0.1-1 \times 10^{4}$ & $0.046,0.013$ & $3.2 \%, 2 \%$ & $\begin{array}{c}99.4 \%, 98.4 \% \text { (15 } \\
\text { days) }\end{array}$ & Hsine et al., 2020 \\
\hline Graphene & $\mathrm{AA}, \mathrm{UA}$ & $1 \times 10^{3}$ to $1.5 \times 10^{4}$ & $0.049,0.047$ & $4.2 \%, 2.7 \%$ & - & Demirkan et al., 2020 \\
\hline Graphene & Leptin & $1.5 \times 10^{-7}$ to $2.5 \times 10^{-3}$ & $3.6 \times 10^{-8}$ & $6.27 \%$ & $92.32 \%$ (7 days) & Cai et al., 2019 \\
\hline Graphene & Acetaminophen & $0.05-0.8$ & $\begin{array}{l}1.4 \times 10^{-4} \\
\left( \pm 5 \times 10^{-5}\right)\end{array}$ & $<4.4 \%$ & $\begin{array}{c}93.11 \pm 2 \% \\
(12 \text { weeks })\end{array}$ & Kumar et al., 2019 \\
\hline Graphene & Glucose & $1-100$ & 0.018 & - & 91\% (20 days) & Baek et al., 2020 \\
\hline Graphene & Glucose & $1,000-1 \times 10^{4}$ & 64 & $0.91 \%$ & 96\% (30 days) & Maity et al., 2019 \\
\hline Graphene & Glucose & $250-8,000$ & - & $4.50 \%$ & 95\% (15 days) & Wang et al., 2019 \\
\hline Graphene & $3-\mathrm{HB}$ & $10-400$ & 1 & $4.50 \%$ & 20 days & Martinez-Garcia et al., 2017 \\
\hline Graphene & Vitamin C & $40-4,100$ & 0.234 & - & 94\% (50 days) & Das et al., 2018 \\
\hline CQDs & UA & $0.21-13.39$ & 1.3 & - & - & Algarra et al., 2018 \\
\hline CQDs & AA & $10-3,000,4,000-12,000$ & 10 & $3.58 \%$ & - & Wei et al., 2019 \\
\hline CQDs & Glucose & $50-2,850$ & 17 & $5.20 \%$ & - & Buk et al., 2019 \\
\hline $\mathrm{C60}$ & Glucose & $10-3,000,3,000-1.1 \times 10^{4}$ & 4.3 & $1.16 \%$ & 93\% (30 days) & Shahhoseini et al., 2019 \\
\hline C60 & Vitamin D-3 & $1.25-475$ & 0.0025 & $2.27 \%$ & 94.25\% (35 days) & Anusha et al., 2020 \\
\hline Carbon nitride & Glucose & $50-2,000$ & 5 & $2.50 \%$ & $90 \%$ (1 month) & Tian et al., 2019 \\
\hline Carbon nitride & Glucose & $0-100$ & 0.29 & - & - & Xian et al., 2019 \\
\hline
\end{tabular}

and MWCNTs to detect UA. Owing to the PCN obtained by this method had the advantages of large specific surface area, excellent dispersion, favorable for electrocatalysis, and outstanding biocompatibility, the conductive properties of PCN were improved by using MWCNTs as conductive substrates. Zhang S. et al. (2019) prepared a novel electrochemical sensor that can detect AA and UA simultaneously. In the presence of MWCNTs, nanocomposites were prepared by in-situ oxidation polymerization of $\mathrm{N}$-(ferrocenyl formyl) pyrrole. This biosensor has the potential to be a helpful tool for simultaneously detecting $\mathrm{AA}$ and UA. In addition to using metal ions, uricase can also be used as a carrier to detect UA. For example, Fukuda et al. (2020) used CNTs and uricase to form an electriccurrent thin film biosensor. The data detected from actual physiological samples were quantified and plotted, which were consistent with the data collected from conventional analytical methods (enzyme colorimetry kit). Manjunatha et al. (2018) constructed electrochemical biosensors by manufacturing a stable electroactive thin film of polymer onto the surface of carbon nanotubes paste electrode. Compared with bare electrode, the improved electrode had enhanced peak current and clear peak separation.

\section{Graphene}

Graphene, as a novel nanomaterial, has received considerable attention since its successful separation (Meng et al., 2016; Saleh and Fadillah, 2019). Moreover, it has the advantages of high electron mobility, high strength, and flexibility, and plays a crucial role in biological sensing applications (Mackin and Palacios, 2016; Hou et al., 2017). At present, graphene is an important material for basic science (AlAqad et al., 2017; Zhao et al., 2018).

For UA detection, Pang et al. (2020) constructed an electrochemical sensor using a composite selfassembled from nitrogen-doped graphene/polyelectrolyte polydiallyldimethylammonium/gold nanoparticles. According to the experimental results, the prepared nanocomposites had obvious electrical activity, reproducibility, and sensitivity to UA oxidation which suggested that the sensor had the potential to diagnose uric acid-related diseases. In 2019, Sriram et al. (2019) modified reduced graphene oxide and superactive iron oxide nanospheres to assemble a novel nanocomposite, which was used to detect UA. According to the characterization results, the improved electrode had an eminent electrochemical reduction peak. In the same year, Verma et al. (2019) used gold 
nanoparticles to decorate graphene oxide nanocomposite thin films, which were covalently immobilized with uricase enzyme to detect UA sensitively and selectively. The interference in the real samples was evaluated, and the mixed samples were measured by UA. This biosensor had a favorable repeatability, indicating a promising future for gold nanocomposites as effective sensor substrates for biosensor applications. Hsine et al. (2020) designed an efficient and simple nanocomposite material, which was a combination of reduced graphene oxide and redox poly (para-phenylene) (Fc-ac-PP) modified with ferrrocenyl group $\mathrm{CRGO} / \mathrm{Fc}$-ac-PPP in a lateral position. The nanocomposites were able to detect AA and UA in a co-existing system by using the separated redox peaks. Demirkan et al. (2020) also detected AA and UA by preparing a novel electrochemical sensor, which was made by modifying palladium nanoparticles supported by polypyrrole/pd-reduced graphene oxide on glassy carbon electrode. Satisfactory results had been obtained when the sensor detected AA and UA in real urine samples in vivo, whether the concentration is high or not.

For the detection of vitamin C, Das et al. (2018) used the nanocomposite of iron oxide-polyvinyl alcohol to modify graphene. The SWV technique was used for detecting the biomolecule which showed that this material provided excellent results for detection of vitamin C. For the detection of NAFLD, Cai et al. (2019) prepared an environmentally friendly and unlabeled immunosensor, which was made of a composite material for the detection of leptin. This composite material was conjugated by strongly coupling between porous graphene surface plasma and anisotropic black phosphorus local surface plasma. Leptin antibodies can be firmly immobilized by the crosslinking of glutaraldehyde. Acetaminophen can be also used as a biomarker for the NAFLD, for which Kumar et al. (2019) developed an electrochemical sensor probe to detect acetaminophen. They used a crucible method to directly synthesize monodisperse iron-gold bimetallic nanoparticles, which were then impregnated with reduced graphene and coated with glassy carbon electrode. The sensor had excellent stability up to 12 weeks. Therefore, the developed sensor system had numerous outstanding characteristics, which can be widely used in clinical and pharmaceutical samples. Baek et al. (2020) constructed a biosensor by synthesizing the excellent nanocomposites to detect glucose. They used copper-nanoflower to decorate gold nanoparticles-graphene oxide nanofiber. Based on the experimental results, the improved sensor can be used to monitor glucose levels in biological fluids for real clinical care site tests. Maity et al. (2019) established a highly sensitive glucose biosensor by using an amine terminated MWCNTs/polyaniline/reduced graphene oxide/gold nanoparticles to modify screen-printed carbon electrode followed by linking glucose oxidase on the surface of electrode. Wang et al. (2019) developed a new nanomaterial by meso-cellular silicate and foam reduced graphene oxide to detect glucose, which exhibited good analytical performance for the detection of glucose. In addition, blood glucose detection in samples of human serum was successfully achieved using this sensor. The schematic diagram is shown in Figure 2.
Martinez-Garcia et al. (2017) prepared a biosensor for the detection of 3-HB by the screen-printed carbon electrode and reduced graphene oxide. An obvious result was that the improved biosensor had advantages in sensitivity compared with the bare sensor.

\section{Carbon Quantum Dots}

Carbon quantum dots (CQDs) have been of great interest to the research community for their unique properties since they were discovered in 2004 (Algarra et al., 2018). CQDs have attracted much attention for their excellent performance such as the outstanding biocompatibility (Rombout et al., 2014; Hou et al., 2018; Zheng et al., 2018). The diameter of CQDs is $<10 \mathrm{~nm}$ and the ratio of surface to volume is large. In addition, the surface of most CQDs contains free groups, with excellent water solubility and surface modification (Li et al., 2012; Zou et al., 2020).

Algarra et al. (2018) developed an innovative biosensor to detect UA. They used the CQDs to modify the original electrode. Fourier infrared, Fluorescence, and Raman spectra were used to characterize this material. Owing to large number of carboxyl groups on the surface of CQDs, the sensitivity of this modified glassy carbon electrode was almost 10 times that of the unmodified glassy carbon electrode. In the second year, Wei et al. (2019) established a new electrochemical sensor to quickly and accurately detect AA. CQDs were synthesized by the new method which was decorated to a glass carbon electrode by electrodeposition. Meanwhile, Buk et al. (2019) developed a new electrochemical biosensor using a hybrid nanomaterial, which was based on CQDs and gold nanoparticles. They selected glucose oxidase as a model system to validate the potential of CQDs as an immobilized substrate. According to the result, the improved biosensor had obvious advantages in the sensitivity.

\section{Fullerene}

Fullerene, also known as $\mathrm{C} 60$, is a three-dimensional composite material with unique cage structure. Owing to its unique molecular configuration, its physical and chemical properties are also special (Afreen et al., 2015; Liu G.F. et al., 2018). It has a wide range of applications in nanomedicine, renewable energy industry, and electrochemical detection (Zheng et al., 2017; Xie and Zhou, 2018).

Shahhoseini et al. (2019) developed a new non-enzymatic electrocatalytic biosensor using $\mathrm{C} 60$ and $\mathrm{Ni}$ (II)-one dimensional coordination polymer. This electrochemical sensor yielded very high results that the improved biosensor had obvious advantages in the stability and sensitivity. As for vitamin D3, Anusha et al. (2020) designed fullerene and copper-nickel bimetallic nanoparticles nanocomposite film modified glassy carbon electrode as an electrochemical sensor. The fabricated sensor employed for real samples that showed satisfactory results for the detection of vitamin D-3 in clinical and pharmaceutical samples.

\section{Carbon Nitride}

Carbon nitride is a 2D material with special electrical properties due to its higher nitrogen content. It can be useful for various 


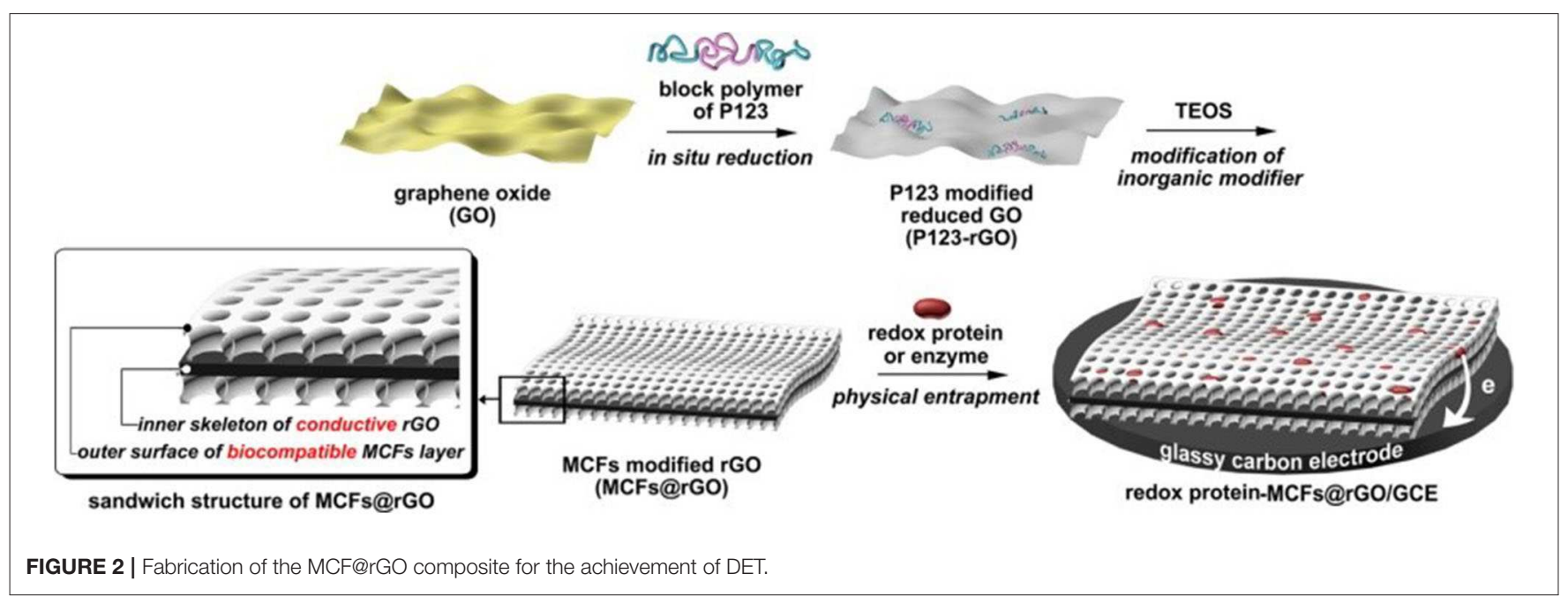

applications, particularly in energy-related fields (Heo et al., 2020).

Tian et al. (2019) synthesized 2-dimensional graphitic carbon nitride through hydrothermal method to detect glucose, and the detection limit was evaluated as $5 \mu \mathrm{M}$. However, Xian et al. (2019) detected glucose by developing irson-doped carbon nitride nanoparticles which were prepared from citric acid, urea, and ferric chloride through a convenient onepot solvothermal method, a novel sensitive method for the detection of glucose with a limit of detection of $0.29 \mu \mathrm{M}$ has been developed. The carbon nitride with mixed iron were more sensitive.

\section{SUMMARY AND OUTLOOK}

In summary, we summarized the latest research progress of electrochemical sensors based on carbon nanomaterials in metabolic disease markers in the last 3 years including carbon nanotubes, graphene, carbon quantum dots, fullerenes, and carbon nitrates. Metabolic diseases not only affect normal diet and life of people but also seriously threaten human health and safety. In addition to maintaining a healthy lifestyle and eating with a healthy diet, early diagnosis of the markers of metabolic disease is also essential which mainly include glucose, uric acid, leptin, and various vitamins. As a result, it is of great significance to develop prompt and sensitive early diagnosis and detection technology to control these diseases.

So far, the electrochemical immunosensor used to analyze actual samples has been widely reported, especially for the

\section{REFERENCES}

Abellan-Llobregat, A., Gonzalez-Gaitan, C., Vidal, L., Canals, A., and Morallon, E. (2018). Portable electrochemical sensor based on 4aminobenzoic acid-functionalized herringbone carbon nanotubes for the determination of ascorbic acid and uric acid in human fluids. Biosens. Bioelectron 109, 123-131. doi: 10.1016/j.bios.2018. 02.047 detection of glucose and ascorbic acid. Generally speaking, its minimum detection threshold is lower than that of other traditional methods. However, due to some technical and commercial reasons, electrochemical immunosensors have not become the mainstream of practical application. For example, the reproducibility and stability of many electrochemical immunosensors prepared as shown in Table 1 are not mentioned, so it is a new challenge to improve the stability and reproducibility of the electrode interface. Moreover, the miniature or portable electrochemical devices are rarely reported for the diagnosis of metabolic diseases, especially for clinical application. Therefore, the research on development of portable, low-cost nano-electrochemical sensors for the diagnosis of metabolic disease has the potential to become a major focus of the research in the near future.

\section{AUTHOR CONTRIBUTIONS}

CZ: conceptualization and writing-original draft preparation. $\mathrm{XD}$ : validation, writing-review and editing, and project administration. All authors contributed to the article and approved the submitted version.

\section{FUNDING}

This work was supported by grants from the National Natural Science Foundation of China (Grant No. 31801137) and Shandong Provincial Natural Science Foundation (ZR2017BC052). 
AlAqad, K. M., Abulkibash, A. M., Al Hamouz, O. C., and Saleh, T. A. (2017). Silver nanoparticles decorated graphene modified carbon paste electrode for molecular methimazole determination. Chem. Date Collect. 168-182. doi: 10.1016/j.cdc.2017.09.003

Algarra, M., Gonzalez-Calabuig, A., Radotic, K., Mutavdzic, D., Ania, C. O., Lazaro-Martinez, J. M., et al. (2018). Enhanced electrochemical response of carbon quantum dot modified electrodes. Talanta 178, 679-685. doi: 10.1016/j.talanta.2017.09.082

Anusha, T., Bhavani, K. S., Kumar, J. V. S., and Brahman, P. K. (2020). Designing and fabrication of electrochemical nanosensor employing fullerene-C-60 and bimetallic nanoparticles composite film for the detection of vitamin D-3 in blood samples. Diam. Relat. Mater 104:107761. doi: 10.1016/j.diamond.2020.107761

Baek, S. H., Roh, J., Park, C. Y., Kim, M. W., Shi, R., Kailasa, S. K., et al. (2020). $\mathrm{Cu}$-nanoflower decorated gold nanoparticles-graphene oxide nanofiber as electrochemical biosensor for glucose detection. Mater. Sci. Eng. C. 107:110273. doi: 10.1016/j.msec.2019.110273

Bouillon, R., Marcocci, C., Carmeliet, G., Bikle, D., White, J. H., DawsonHughes, B., et al. (2019). Skeletal and extraskeletal actions of vitamin D: current evidence and outstanding questions. Endocr. Rev. 40, 1109-1151. doi: 10.1210/er.2018-00126

Buk, V., Pemble, M. E., and Twomey, K. (2019). Fabrication and evaluation of a carbon quantum dot/gold nanoparticle nanohybrid material integrated onto planar micro gold electrodes for potential bioelectrochemical sensing applications. Electrochim. Acta 293, 307-317. doi: 10.1016/j.electacta.2018.10.038

Cai, J., Gou, X., Sun, B., Li, W., Li, D., Liu, J., et al. (2019). Porous grapheneblack phosphorus nanocomposite modified electrode for detection of leptin. Biosens. Bioelectron 137, 88-95. doi: 10.1016/j.bios.2019. 04.045

Cani, P. D. (2019). Microbiota and metabolites in metabolic diseases. Nat. Rev. Endocrinol. 15, 69-70. doi: 10.1038/s41574-0180143-9

Chen, K., Gao, W., Emaminejad, S., Kiriya, D., Ota, H., Nyein, H. Y., et al. (2016a). Carbon nanotubes: printed carbon nanotube electronics and sensor systems. Adv. Mater. 28:4396. doi: 10.1002/adma.201670151

Chen, K., Gao, W., Emaminejad, S., Kiriya, D., Ota, H., Nyein, H. Y., et al. (2016b). Printed carbon nanotube electronics and sensor systems. Adv. Mater. 28, 4397-4414. doi: 10.1002/adma.201504958

Clemmensen, C., Finan, B., Muller, T. D., DiMarchi, R. D., Tschop, M. H., and Hofmann, S. M. (2019). Emerging hormonal-based combination pharmacotherapies for the treatment of metabolic diseases. Nat. Rev. Endocrinol. 15, 90-104. doi: 10.1038/s41574-018-0118-x

Colca, J. (2020). NASH (nonalcoholic steatohepatitis), diabetes, and macrovascular disease: multiple chronic conditions and a potential treatment at the metabolic root. Expert Opin. Investig. Drugs 29, 191-196. doi: 10.1080/13543784.2020.1715940

Cui, L. L., Yang, G. W., Pan, J., and Zhang, C. (2011). Tumor necrosis factor alpha knockout increases fertility of mice. Theriogenology 75, 867-876. doi: 10.1016/j.theriogenology.2010.10.029

Das, T. R., Jena, S. K., Madhuri, R., and Sharma, P. K. (2018). Polymeric iron oxidegraphene nanocomposite as a trace level sensor of vitamin C. Appl. Surf. Sci. 449 304-313. doi: 10.1016/j.apsusc.2018.01.173

De Volder, M. F., Tawfick, S. H., Baughman, R. H., and Hart, A. J. (2013). Carbon nanotubes: present and future commercial applications. Science 339, 535-539. doi: $10.1126 /$ science. 1222453

Demirkan, B., Bozkurt, S., Cellat, K., Arikan, K., Yilmaz, M., Savk, A., et al. (2020). Palladium supported on polypyrrole/reduced graphene oxide nanoparticles for simultaneous biosensing application of ascorbic acid, dopamine, and uric acid. Sci. Rep. 10:2946. doi: 10.1038/s41598-02059935-y

Ding, N. Z., Qi, Q. R., Gu, X. W., Zuo, R. J., Liu, J., and Yang, Z. M. (2018). De novo synthesis of sphingolipids is essential for decidualization in mice. Theriogenology 106, 227-236. doi: 10.1016/j.theriogenology.2017. 09.036

Ding, X., Niu, Y., Zhang, G., Xu, Y., and Li, J. (2020). Electrochemistry in carbon-based quantum dots. Chem. Asian J. 15, 1214-1224. doi: 10.1002/asia.202000097
Du, X., Zhang, Z., Zheng, X., Zhang, H., Dong, D., Zhang, Z., et al. (2020). An electrochemical biosensor for the detection of epithelial-mesenchymal transition. Nat. Commun. 11:192. doi: 10.1038/s41467-019-14037-w

Du, X., and Zhou, J. (2018). Application of biosensors to detection of epidemic diseases in animals. Res. Vet. Sci. 118, 444-448. doi: 10.1016/j.rvsc.2018.04.011

El-Nashar, R. M., Abdel Ghani, N. T., and Hassan, S. M. (2012). Construction and performance characteristics of new ion selective electrodes based on carbon nanotubes for determination of meclofenoxate hydrochloride. Anal. Chim. Acta 730, 99-111. doi: 10.1016/j.aca.2011.10.069

Fukuda, T., Muguruma, H., Iwasa, H., Tanaka, T., Hiratsuka, A., Shimizu, T., et al. (2020). Electrochemical determination of uric acid in urine and serum with uricase/carbon nanotube/carboxymethylcellulose electrode. Anal. Biochem. 590:113533. doi: 10.1016/j.ab.2019.113533

Gong, H., Peng, R., and Liu, Z. (2013). Carbon nanotubes for biomedical imaging: the recent advances. Adv. Drug Deliv. Rev. 65, 1951-1963. doi: 10.1016/j.addr.2013.10.002

Guo, T., Zhang, L., Cheng, D., Liu, T., An, L. G., Li, W. P., et al. (2015). Low-density lipoprotein receptor affects the fertility of female mice. Reprod. Fertil. Dev. 27, 1222-1232. doi: 10.1071/RD13436

Heo, N. S., Song, H. P., Lee, S. M., Cho, H. J., Kim, H. J., Huh, Y. S., et al. (2020). Rosette-shaped graphitic carbon nitride acts as a peroxidase mimic in a wide $\mathrm{pH}$ range for fluorescence-based determination of glucose with glucose oxidase. Microchim. Acta 187:286. doi: 10.1007/s00604-020-04249-z

Hou, P. L., Wang, H. M., Zhao, G. M., He, C. Q., and He, H. B. (2017). Rapid detection of infectious bovine rhinotracheitis virus using recombinase polymerase amplification assays. BMC Vet. Res. 13:386. doi: 10.1186/s12917-017-1284-0

Hou, P. L., Zhao, G. M., Wang, H. M., He, C. Q., and He, H. B. (2018). Rapid detection of bovine viral diarrhea virus using recombinase polymerase amplification combined with lateral flow dipstick assays in bulk milk. Vet. Arh. 88, 627-642. doi: 10.24099/vet.arhiv.0145

Hsine, Z., Bizid, S., Milka, R., Sauriat-Dorizon, H., Haj Said, A., and Korri-Youssoufi, H. (2020). Nanocomposite based on poly (paraphenylene)/chemical reduced graphene oxide as a platform for simultaneous detection of ascorbic acid, dopamine and uric acid. Sensors 20:1256. doi: $10.3390 /$ s20051256

Iranmanesh, T., Foroughi, M. M., Jahani, S., Shahidi Zandi, M., and Hassani Nadiki, H. (2020). Green and facile microwave solvent-free synthesis of $\mathrm{CeO}_{2}$ nanoparticle-decorated CNTs as a quadruplet electrochemical platform for ultrasensitive and simultaneous detection of ascorbic acid, dopamine, uric acid and acetaminophen. Talanta 207:120318. doi: 10.1016/j.talanta.2019.120318

Janegitz, B. C., Silva, T. A., Wong, A., Ribovski, L., Vicentini, F. C., Taboada Sotomayor, M. D. P., et al. (2017). The application of graphene for in vitro and in vivo electrochemical biosensing. Biosens. Bioelectron 89(Pt 1), 224-233. doi: 10.1016/j.bios.2016.03.026

Kawase, T., Tanaka, K., Seirai, Y., Shiono, N., and Oda, M. (2003). Complexation of carbon nanorings with fullerenes: supramolecular dynamics and structural tuning for a fullerene sensor. Angew. Chem. Int. Ed. Engl. 42, 5597-5600. doi: 10.1002/anie.200352033

Kim, K. T., Kang, K. C., Shin, D. E., Lee, S. H., Lee, J. H., and Kwon, T. Y. (2015). Prevalence of vitamin D deficiency and its association with metabolic disease in korean orthopedic patients. Orthopedics 38, e898-903. doi: 10.3928/01477447-20151002-57

Kumar, A., Purohit, B., Mahato, K., Mandal, R., Srivastava, A., and Chandra, P. (2019). Gold-iron bimetallic nanoparticles impregnated reduced graphene oxide based nanosensor for label-free detection of biomarker related to non-alcoholic fatty liver disease. Electroanalysis 31, 2417-2428. doi: 10.1002/elan.201900337

Li, L., Yang, H. J., Liu, D. C., He, H. B., Wang, C. F., Zhong, J. F., et al. (2012). Analysis of biofilms formation and associated genes detection in Staphylococcus isolates from bovine mastitis. Int. J. Appl. Res. Vet. Med. 10, 62-68. doi: 10.5897/AJB11.081

Liang, J. W., Tian, F. L., Lan, Z. R., Huang, B., and Zhuang, W. Z. (2010). Selection characterization on overlapping reading frame of multiple-proteinencoding $\mathrm{P}$ gene in newcastle disease virus. Vet. Microbiol. 144, 257-263. doi: 10.1016/j.vetmic.2009.12.029

Liu, G. F., Liu, X. M., Shahzad, K., You, W., Loor, J. J., and Wan, F. C. (2018). Bioinformatics analyses of bovine adipose tissue transcriptome from 
lilu beef cattle at different stages of growth. Pak. J. Zool 50, 1847-1855. doi: 10.17582/journal.pjz/2018.50.5.1847.1855

Liu, M., Xie, S. B., and Zhou, J. (2018). Use of animal models for the imaging and quantification of angiogenesis. Exp. Anim. 67, 1-6. doi: 10.1538/expanim.17-0054

Liu, S. L., Oyama, T., Miyoshi, Y., Sheu, S. Y., Mita, M., Ide, T., et al. (2015). Establishment of a two-dimensional chiral HPLC system for the simultaneous detection of lactate and 3-hydroxybutyrate enantiomers in human clinical samples. J. Pharm. Biomed. Anal. 116, 80-85. doi: 10.1016/j.jpba.2015.05.036

Lv, J., Li, C., Feng, S., Chen, S.-M., Ding, Y., Chen, C., et al. (2019). A novel electrochemical sensor for uric acid detection based on PCN/MWCNT. Zhongguo Fei Ai Za Zhi 25, 4437-4445. doi: 10.1007/s11581-019-03010-8

Mackin, C., and Palacios, T. (2016). Large-scale sensor systems based on graphene electrolyte-gated field-effect transistors. Analyst 141, 2704-2711. doi: 10.1039/C5AN02328A

Maduraiveeran, G., Sasidharan, M., and Ganesan, V. (2018). Electrochemical sensor and biosensor platforms based on advanced nanomaterials for biological and biomedical applications. Biosens. Bioelectron 103, 113-129. doi: 10.1016/j.bios.2017.12.031

Maessen, D. E., Stehouwer, C. D., and Schalkwijk, C. G. (2015). The role of methylglyoxal and the glyoxalase system in diabetes and other age-related diseases. Clin. Sci. 128, 839-861. doi: 10.1042/CS20140683

Maiese, K. (2020). Cognitive impairment with diabetes mellitus and metabolic disease: innovative insights with the mechanistic target of rapamycin and circadian clock gene pathways. Expert Rev. Clin. Pharmacol. 13, 23-34. doi: $10.1080 / 17512433.2020 .1698288$

Maity, D., Minitha, C. R., and Rajendra Kumar, T. R. (2019). Glucose oxidase immobilized amine terminated multiwall carbon nanotubes/reduced graphene oxide/polyaniline/gold nanoparticles modified screen-printed carbon electrode for highly sensitive amperometric glucose detection. Mater. Sci. Eng. C Mater. Biol. Appl. 105:110075. doi: 10.1016/j.msec.2019.110075

Manjunatha, J. G., Deraman, M., Basri, N. H., and Talib, I. A. (2018). Fabrication of poly (Solid Red A) modified carbon nano tube paste electrode and its application for simultaneous determination of epinephrine, uric acid and ascorbic acid. Arab. J. Chem. 11, 149-158. doi: 10.1016/j.arabjc.2014.10.009

Martinez-Garcia, G., Perez-Julian, E., Agui, L., Cabre, N., Joven, J., Yanez-Sedeno, P., et al. (2017). An electrochemical enzyme biosensor for 3-hydroxybutyrate detection using screen-printed electrodes modified by reduced graphene oxide and thionine. Biosens. Basel 7:50. doi: 10.3390/bios7040050

Meng, X. Q., Dai, Y. Y., Jing, L. D., Bai, J., Liu, S. Z., Zheng, K. G., et al. (2016). Subcellular localization of proline-rich tyrosine kinase 2 during oocyte fertilization and early-embryo development in mice. J. Reprod. Dev. 62, 351-358. doi: 10.1262/jrd.2016-015

Musso, G., Gambino, R., Cassader, M., and Paschetta, E. (2019). Efficacy and safety of dual SGLT 1/2 inhibitor sotagliflozin in type 1 diabetes: meta-analysis of randomised controlled trials. BMJ 365:11328. doi: 10.1136/bmj.11328

Noyce, S. G., Doherty, J. L., Cheng, Z., Han, H., Bowen, S., and Franklin, A. D. (2019). Electronic stability of carbon nanotube transistors under long-term bias stress. Nano Lett. 19, 1460-1466. doi: 10.1021/acs.nanolett.8b03986

Oh, H., Park, J., Yoon, Y., and Seo, W. (2019). Comparisons of the incidence and critical risk factors of metabolic syndrome in patients with a rheumatic disease or gout. Orthop. Nurs. 38, 201-208. doi: 10.1097/NOR.0000000000000557

Pang, X., Li, F., Huang, S., Yang, Z., Mo, Q., Huang, L., et al. (2020). Electrostatically mediated layer-by-layer assembly of nitrogen-doped graphene/PDDA/gold nanoparticle composites for electrochemical detection of uric acid. Anal. Bioanal. Chem. 412, 669-680. doi: 10.1007/s00216-019-02275-2

Perez-Perez, A., Vilarino-Garcia, T., Fernandez-Riejos, P., Martin-Gonzalez, J., Jose Segura-Egea, J., and Sanchez-Margalet, V. (2017). Role of leptin as a link between metabolism and the immune system. Cytokine Growth Factor Rev. 35, 71-84. doi: 10.1016/j.cytogfr.2017.03.001

Pittas, A. G., Dawson-Hughes, B., Sheehan, P., Ware, J. H., Knowler, W. C., Aroda, V. R., et al. (2019). Vitamin D supplementation and prevention of type 2 diabetes. N. Engl. J. Med. 381, 520-530. doi: 10.1056/NEJMoa 1900906

Quintero-Jaime, A. F., Berenguer-Murcia, A., Cazorla-Amoros, D., and Morallon, E. (2019). Carbon nanotubes modified with au for electrochemical detection of prostate specific antigen: effect of Au nanoparticle size distribution. Front. Chem. 7:147. doi: 10.3389/fchem.2019.00147
Rajabi, H., and Noroozifar, M. (2017). New synthesis of poly ortho-methoxyaniline nanostructures and its application to construct modified multi-wall carbon nanotube/graphite paste electrode for simultaneous determination of uric acid and folic acid. Mater. Sci. Eng. C 75,791-797 doi: 10.1016/j.msec.2017.02.133

Ren, Q. (2015). A new species and new records of the lichen genus Pertusaria from China. Mycotaxon 130, 689-693. doi: 10.5248/130.689

Rodriguez-Gallego, E., Guirro, M., Riera-Borrull, M., Hernandez-Aguilera, A., Marine-Casado, R., Fernandez-Arroyo, S., et al. (2015). Mapping of the circulating metabolome reveals alpha-ketoglutarate as a predictor of morbid obesity-associated non-alcoholic fatty liver disease. Int. J. Obes. 39, 279-287. doi: 10.1038/ijo.2014.53

Rombout, J., Yang, G. W., and Kiron, V. (2014). Adaptive immune responses at mucosal surfaces of teleost fish. Fish Shellfish Immunol. 40, 634-643. doi: 10.1016/j.fsi.2014.08.020

Rosik, J., Szostak, B., Machaj, F., and Pawlik, A. (2020). The role of genetics and epigenetics in the pathogenesis of gestational diabetes mellitus. Ann. Hum. Genet. 84, 114-124. doi: 10.1111/ahg. 12356

Sahin, S., Merotra, J., Kang, J., Trenell, M., Catt, M., and Yu, E. H. (2018). Simultaneous electrochemical detection of glucose and Non-Esterified Fatty Acids (NEFAs) for diabetes management. IEEE Sens. J. 18, 9075-9080. doi: $10.1109 /$ JSEN.2018.2870071

Saleh, T. A., and Fadillah, G. (2019). Recent trends in the design of chemical sensors based on graphene-metal oxide nanocomposites for the analysis of toxic species and biomolecules. Trac Trends Analy. Chem. 120:115660. doi: 10.1016/j.trac.2019.115660

Salek-Maghsoudi, A., Vakhshiteh, F., Torabi, R., Hassani, S., Ganjali, M. R., Norouzi, P., et al. (2018). Recent advances in biosensor technology in assessment of early diabetes biomarkers. Biosens. Bioelectr. 99, 122-135. doi: 10.1016/j.bios.2017.07.047

Sanna, S., van Zuydam, N. R., Mahajan, A., Kurilshikov, A., Vila, A. V., Vosa, U., et al. (2019). Causal relationships among the gut microbiome, short-chain fatty acids and metabolic diseases. Nat. Genet. 51, 600-605. doi: 10.1038/s41588-019-0350-x

Sassi, F., Tamone, C., and D'Amelio, P. (2018). Vitamin D: nutrient, hormone, and immunomodulator. Nutrients 10:1656. doi: 10.3390/nu10111656

Shahhoseini, L., Mohammadi, R., Ghanbari, B., and Shahrokhian, S. (2019). Ni(II) 1D-coordination polymer/C-60-modified glassy carbon electrode as a highly sensitive non-enzymatic glucose electrochemical sensor. Appl. Surf. Sci. 478, 361-372. doi: 10.1016/j.apsusc.2019.01.240

Sriram, B., Govindasamy, M., Wang, S. F., Jothi Ramalingam, R., Al-Lohedan, H., and Maiyalagan, T. (2019). Novel sonochemical synthesis of Fe3O4 nanospheres decorated on highly active reduced graphene oxide nanosheets for sensitive detection of uric acid in biological samples. Ultrason. Sonochem. 58:104618. doi: 10.1016/j.ultsonch.2019.104618

Taniselass, S., Arshad, M. K. M., and Gopinath, S. C. B. (2019). Graphenebased electrochemical biosensors for monitoring noncommunicable disease biomarkers. Biosens. Bioelectron 130, 276-292. doi: 10.1016/j.bios.2019.01.047

Tian, K. J., Liu, H., Dong, Y. P., Chu, X. F., and Wang, S. B. (2019). Amperometric detection of glucose based on immobilizing glucose oxidase on g-C3N4 nanosheets. Colloids Surf. A 581:123808. doi: 10.1016/j.colsurfa.2019.123808

Tilmaciu, C. M., and Morris, M. C. (2015). Carbon nanotube biosensors. Front. Chem. 3:59. doi: 10.3389/fchem.2015.00059

Verma, S., Choudhary, J., Singh, K. P., Chandra, P., and Singh, S. P. (2019). Uricase grafted nanoconducting matrix based electrochemical biosensor for ultrafast uric acid detection in human serum samples. Int. J. Biol. Macromol. 130, 333-341. doi: 10.1016/j.ijbiomac.2019.02.121

Wang, H. M., Hou, P. L., Zhao, G. M., Yu, L., Gao, Y. W., and He, H. B. (2018). Development and evaluation of serotype-specific recombinase polymerase amplification combined with lateral flow dipstick assays for the diagnosis of foot-and-mouth disease virus serotype A, O and Asial. BMC Vet. Res. 14:359. doi: 10.1186/s12917-018-1644-4

Wang, H. T., Teng, F., Zhang, L., Zhang, Q., Zhang, H. R., Pei, T. T., et al. (2019). Meso-cellular silicate foam-modified reduced graphene oxide with a sandwich structure for enzymatic immobilization and bioelectrocatalysis. Acs Appl. Mater. Interfaces 11, 29522-29535. doi: 10.1021/acsami.9b08569

Wei, Y., Zhang, D., Fang, Y., Wang, H., Liu, Y., Xu, Z., et al. (2019). Detection of ascorbic acid using green synthesized carbon quantum dots. J. Sens. 2019:9869682. doi: $10.1155 / 2019 / 9869682$ 
Xian, J. Q., Weng, Y. H., Guo, H. T., Li, Y., Yao, B. X., and Weng, W. (2019). One-pot fabrication of $\mathrm{Fe}$-doped carbon nitride nanoparticles as peroxidase mimetics for $\mathrm{H} 2 \mathrm{O} 2$ and glucose detection. Spectrochim. Acta A 215, 218-224. doi: 10.1016/j.saa.2019.02.046

Xie, W., and Zhou, J. (2018). Aberrant regulation of autophagy in mammalian diseases. Biol. Lett. 14:540. doi: 10.1098/rsbl.2017.0540

Yang, H. T., Zou, S. S., Zhai, L. J., Wang, Y., Zhang, F. M., An, L. G., et al. (2017). Pathogen invasion changes the intestinal microbiota composition and induces innate immune responses in the zebrafish intestine. Fish Shellfish Immunol. 71, 35-42. doi: 10.1016/j.fsi.2017.09.075

Yang, Z., Tian, J., Yin, Z., Cui, C., Qian, W., and Wei, F. (2019). Carbon nanotube- and graphene-based nanomaterials and applications in high-voltage supercapacitor: a review. Carbon N. Y. 141, 467-480. doi: 10.1016/j.carbon.2018.10.010

Zhang, P., Sun, D., Cho, A., Weon, S., Lee, S., Lee, J., et al. (2019). Modified carbon nitride nanozyme as bifunctional glucose oxidase-peroxidase for metal-free bioinspired cascade photocatalysis. Nat. Commun. 10:940. doi: 10.1038/s41467-019-08731-y

Zhang, S., Xu, F., Liu, Z. Q., Chen, Y. S., and Luo, Y. L. (2019). Novel electrochemical sensors from poly[N-(ferrocenyl formacyl) pyrrole]@multiwalled carbon nanotubes nanocomposites for simultaneous determination of ascorbic acid, dopamine and uric acid. Nanotechnology 31:085503. doi: 10.1088/1361-6528/ab53bb

Zhao, G. M., Wang, H. M., Hou, P. L., He, C. Q., and He, H. B. (2018). Rapid visual detection of Mycobacterium avium subsp paratuberculosis by recombinase polymerase amplification combined with a lateral flow dipstick. J. Vet. Sci. 19, 242-250. doi: 10.4142/jvs.2018.19.2.242

Zheng, S., Wu, X., Shi, J., Peng, Z., Gao, M., Xin, C., et al. (2018). Rapid specific and visible detection of porcine circovirus type 3 using loop-mediated isothermal amplification (LAMP). Transbound. Emerg. Dis. 65, 597-601. doi: $10.1111 /$ tbed.12835

Zheng, S., Wu, X., Zhang, L., Xin, C., Liu, Y., Shi, J., et al. (2017). The occurrence of porcine circovirus 3 without clinical infection signs in Shandong Province. Transbound. Emerg. Dis. 64, 1337-1341. doi: 10.1111/tbed. 12667

Zou, S., Guo, F., Wu, L., Ju, H., Sun, M., Cai, R., et al. (2020). One-pot synthesis of cerium and praseodymium co-doped carbon quantum dots as enhanced antioxidant for hydroxyl radical scavenging. Nanotechnology 31:165101. doi: 10.1088/1361-6528/ab5b40

Conflict of Interest: The authors declare that the research was conducted in the absence of any commercial or financial relationships that could be construed as a potential conflict of interest.

Copyright $(2) 2020$ Zhang and Du. This is an open-access article distributed under the terms of the Creative Commons Attribution License (CC BY). The use, distribution or reproduction in other forums is permitted, provided the original author(s) and the copyright owner(s) are credited and that the original publication in this journal is cited, in accordance with accepted academic practice. No use, distribution or reproduction is permitted which does not comply with these terms. 